\title{
Multiple Non-Species-Specific Pathogens Possibly Triggered the Mass Mortality in Pinna nobilis
}

\author{
Fabio Scarpa ${ }^{1, \dagger}$, Daria Sanna ${ }^{2, *,+}$, Ilenia Azzena ${ }^{1,2}$, Davide Mugetti ${ }^{3}$, Francesco Cerruti ${ }^{3}$, \\ Sepideh Hosseini ${ }^{2}{ }^{\mathbb{D}}$, Piero Cossu ${ }^{1}$, Stefania Pinna ${ }^{4}$, Daniele Grech ${ }^{4}$, David Cabana ${ }^{4}$, \\ Viviana Pasquini ${ }^{5}$, Giuseppe Esposito ${ }^{1}$, Nicoletta Cadoni ${ }^{6}$, Fabrizio Atzori ${ }^{6}$, \\ Elisabetta Antuofermo ${ }^{1}$, Piero Addis ${ }^{5}{ }^{(0)}$, Leonardo Antonio Sechi ${ }^{2}{ }^{(1)}$, Marino Prearo ${ }^{3}$, \\ Simone Peletto ${ }^{3}\left(\mathbb{D}\right.$, Marianna A. Mossa ${ }^{7}$, Tiziana Saba ${ }^{7}$, Vittorio Gazale ${ }^{8}$ and Marco Casu ${ }^{1}(\mathbb{D})$ \\ 1 Dipartimento di Medicina Veterinaria, Università degli Studi di Sassari, Via Vienna 2, 07100 Sassari, Italy; \\ fscarpa@uniss.it (F.S.); iazzena@uniss.it (I.A.); picossu@uniss.it (P.C.); gsesposito@uniss.it (G.E.); \\ eantuofermo@uniss.it (E.A.); marcasu@uniss.it (M.C.) \\ 2 Dipartimento di Scienze Biomediche, Università degli Studi di Sassari, Viale San Pietro 43/B, \\ 07100 Sassari, Italy; s.hosseiniporgham@studenti.uniss.it (S.H.); sechila@uniss.it (L.A.S.) \\ 3 Istituto Zooprofilattico Sperimentale del Piemonte, Liguria e Valle d'Aosta, Via Bologna 148, \\ 10154 Torino, Italy; davide.mugetti@izsto.it (D.M.); francesco.cerutti@izsto.it (F.C.); \\ marino.prearo@izsto.it (M.P.); simone.peletto@izsto.it (S.P.) \\ 4 IMC-International Marine Centre, Loc. Sa Mardini, Torregrande, 09170 Oristano, Italy; \\ s.pinna@fondazioneimc.it (S.P.); d.grech@fondazioneimc.it (D.G.); d.cabana@fondazioneimc.it (D.C.) \\ 5 Dipartimento di Scienze della Vita e dell'Ambiente, Università di Cagliari, Via Fiorelli 1, 09126 Cagliari, Italy; \\ vivi.pasquini@yahoo.it (V.P.); addisp@unica.it (P.A.) \\ 6 Area Marina Protetta Capo Carbonara, Comune di Villasimius, Via Roma 60, 09049 Villasimius, Italy; \\ nicolettacadoni@gmail.com (N.C.); direzione@ampcapocarbonara.it (F.A.) \\ 7 Regiona autonoma della Sardegna, Via Roma 80, 09123 Cagliari, Italy; \\ mmossa@regione.sardegna.it (M.A.M.); tsaba@regione.sardegna.it (T.S.) \\ 8 Area Marina Protetta "Isola dell'Asinara”, 07046 Porto Torres, Italy; gazale@asinara.org \\ * Correspondence: darsanna@uniss.it \\ + Fabio Scarpa and Daria Sanna equally contributed to this paper.
}

Received: 5 August 2020; Accepted: 9 October 2020; Published: 13 October 2020

\begin{abstract}
The fan mussel, Pinna nobilis, represents the largest bivalve endemic to the Mediterranean Sea. Since 2016, dramatic mass mortality of this species has been observed in several areas. The first surveys suggested that Haplosporidium pinnae (currently considered species-specific) was the main etiological agent, but recent studies have indicated that a multifactorial disease may be responsible for this phenomenon. In this study, we performed molecular diagnostic analyses on P. nobilis, P. rudis, and bivalve heterologous host species from the island of Sardinia to shed further light on the pathogens involved in the mass mortality. The results support the occurrence of a multifactorial disease and that Mycobacterium spp. and H. pinnae are not necessarily associated with the illness. Indeed, our analyses revealed that $H$. pinnae is not species-specific for P. nobilis, as it was present in other bivalves at least three years before the mass mortality began, and species of Mycobacterium were also found in healthy individuals of $P$. nobilis and P. rudis. We also detected the species Rhodococcus erythropolis, representing the first report in fan mussels of a bacterium other than Mycobacterium spp. and Vibrio spp. These results depict a complicated scenario, further demonstrating how the P. nobilis mass mortality event is far from being fully understood.
\end{abstract}

Keywords: fan mussel; Mycobacterium sp.; Haplosporidium pinnae; Rhodococcus erythropolis; multifactorial disease; Sardinia; heterologous host species; sentinel species; Pinna rudis 


\section{Introduction}

The fan mussel (or noble pen shell), Pinna nobilis Linnaeus, 1758 (Bivalvia: Pinnidae), is one of the best-known marine invertebrates, representing an endemic flagship species for the Mediterranean Sea. The fan mussel is one of the largest bivalves in the world and the largest in the Mediterranean, reaching up to $120 \mathrm{~cm}$ in height [1], and it is one of the most long-lived, living up to 50 years in favorable conditions [2]. Pinna nobilis lives at depths between 0.5 and $60 \mathrm{~m}$ on soft bottoms overgrown by seagrass meadows [3] and occasionally on the bare sandy substrate and maerl beds [4]. The length of the larval life cycle, as well as factors influencing survival rates and behavior, remain poorly understood [5]. In general, the larval duration for the genus Pinna has been estimated to be a maximum of 10 days $[4,6]$. After the veliger stage in which the larvae drift in the water column [7], juveniles settle in the sediment, anchoring via a byssus [6].

In the 1980s, there were large decreases in most populations of $P$. nobilis due to various anthropogenic activities, such as recreational and commercial fishing, ornamental harvesting (the byssus was used by artisanal manufactures of the so-called 'sea silk' [8]), and accidental killing by anchoring and trawl nets [9]. To address the decreased populations, $P$. nobilis was included in a protection regime under the Annex II of the Barcelona Convention (SPA/BD Protocol 1995) and Annex IV of the EU Habitats Directive (European Council Directive 92/43/EEC). More recently, in Italy, the Legislative Decree 190/2010, Art. 11 for the Marine Strategy Monitoring Program included the fan mussel among the Mediterranean species worthy of particular attention. The application of these conservation measures led to the recovery of the populations of $P$. nobilis throughout the entire Mediterranean basin. The results from one of the most recent molecular surveys [10] also supported the good health status of this species, without evidence of genetic fragmentation within and among the main Mediterranean basins $[10,11]$.

Unfortunately, since 2016, dramatic mass mortality of the fan mussel populations has been observed in several Mediterranean areas, from the coasts of Spain eastward [12]. To date, epidemiological surveys have indicated different etiological agents as being responsible for the $P$. nobilis mass mortality, with Haplosporidium pinnae as the primary agent [13-15], followed by Mycobacterium sp. [16], Vibrio spp. [17,18], and Perkinsus spp. [19]. In the first phase of the illness, individuals affected by this unknown disease are characterized by an anomalous slow closure of the valves after external stimulation. In the advanced phases, individuals are no longer able to completely close the valves, becoming highly vulnerable to predation. In the terminal stage, the mantle of the fan mussel detaches from the valves and moves down in the bottom of the shell, after which individuals cannot survive more than a few days (in the absence of predation).

In the Western Mediterranean, until a few years ago, Sardinia Island housed a large number of $P$. nobilis populations, which included thousands of individuals (personal observation during sampling collections for previous studies $[10,11]$, mainly located in national parks and marine protected areas distributed along the coastline of the island). However, the Sardinian populations of P. nobilis have also been rapidly affected by this mass mortality, which dramatically decimated the island's populations of fan mussels [16]. In particular, the case of Asinara Island (north-west of Sardinia) presents a brutal picture of the suddenness and severity of the phenomenon along the Sardinian coasts. Indeed, at the beginning of 2018, during a fan mussel census activity in the Asinara Island promoted by the Marine Strategy Monitoring Program, we detected the first signs of decline in P. nobilis when the total number of individuals at the sampling sites, considered in the present research, was still over 500 [20]. Then, in July 2018, mortality reached about $50 \%$; in November, almost $90 \%$ of individuals were found dead (Figure 1), and their shells were often used as a den for other species. Mass mortality phenomena involving other zoobenthic species (e.g., restricted to bivalves, Arca noae, Spondylus gaederopus, Lithophaga lithophaga, Ostrea edulis, Lima spp.) have been observed in the past. These events were seen as a consequence of the current climate warming trend [21], which affects more than just filter feeders. However, the situation of $P$. nobilis does not properly fall under such cases and cannot be compared with any other known mortality phenomena to date, at least in the Mediterranean. 
Indeed, to our knowledge, such a severe event, with very high mortality rates and wide geographical and temporal distributions, has never been reported in Mediterranean zoobenthic marine taxa, making the need to find a solution to stem (or partially stem) this catastrophic scenario even more urgent.

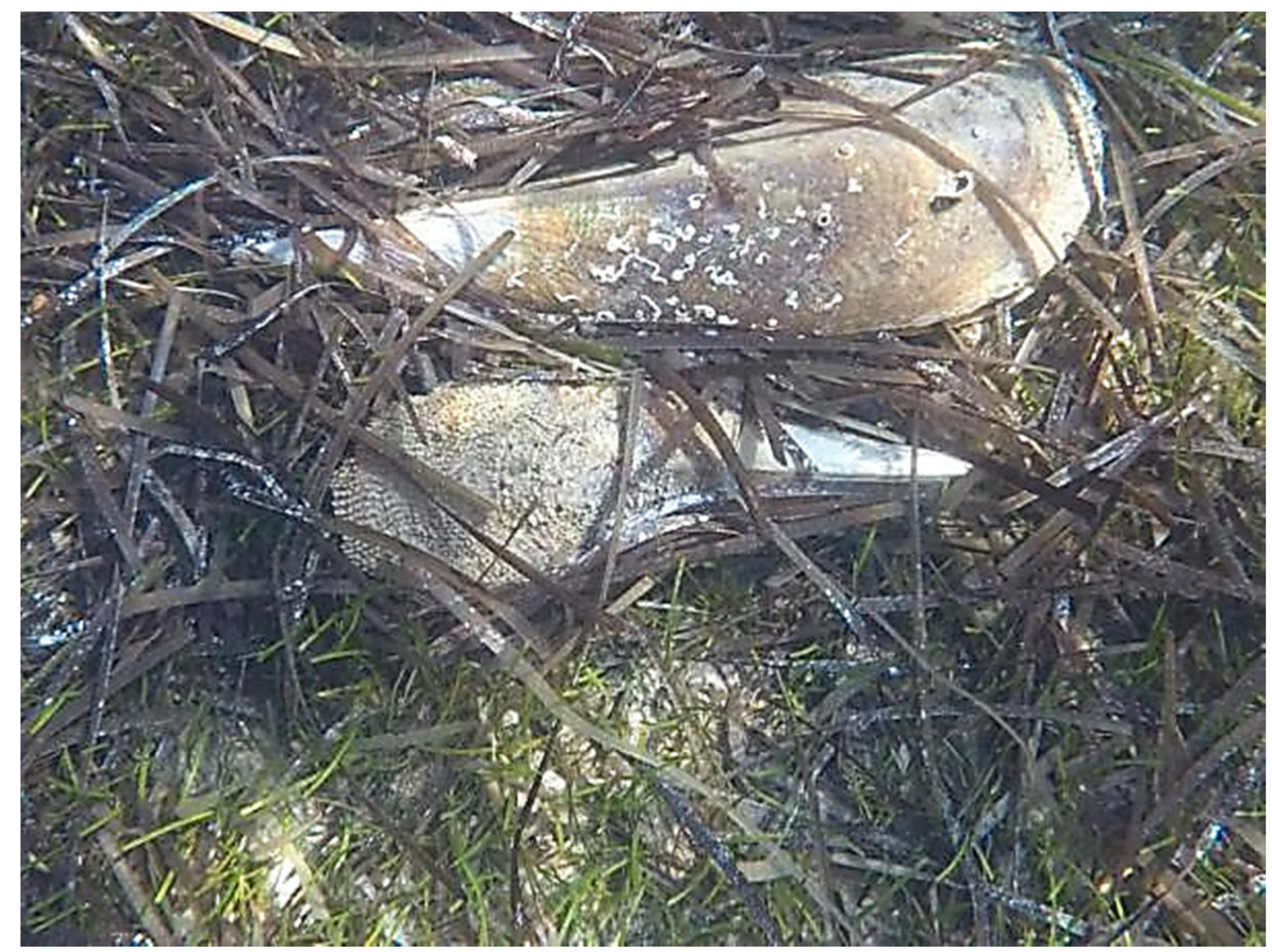

Figure 1. Individuals of Pinna nobilis found dead with shell completely detached from the bottom.

Therefore, in 2019, the government of the Autonomous Region of Sardinia (RAS) promoted an action plan focused on P. nobilis populations on the Sardinian coast to evaluate the impact of the massive mortality on its populations using census activities and diagnostic analyses. The aim of this latter task was to improve the knowledge regarding the factors involved in the disease that is leading P. nobilis to the brink of local extinction in Sardinia and to shed further light on its mass mortality. Indeed, the island of Sardinia, with its central position in the Western Mediterranean basin, represents a strategic site to perform molecular analyses to enable a better understanding of this phenomenon.

In this context, our research focused on molecular surveys on $P$. nobilis samples collected in Sardinia during 2018 and 2019 to provide a more complete picture of the presence of environmental etiological agents that may be affecting local populations of the species. Based on previous studies [14,16,17], we focused our efforts on identifying protozoans and bacteria. In addition, we selected two Mediterranean bivalve heterologous host species as potential 'sentinel organisms' (i.e., Mytilus galloprovincialis, collected in 2019, and Ruditapes decussatus, collected in 2014) to check, using molecular tools, for the presence of infections by etiological agents in bivalves other than the fan mussel, in both the present and past years. Furthermore, samples from two individuals of Pinna rudis were subjected to the same molecular analyses used for $P$. nobilis to verify the possible presence of the etiological agents in a congeneric species. 


\section{Materials and Methods}

\subsection{Sample Collection}

Specimens of P. nobilis were collected in 2018 (from July to December) and 2019 (from April to December) during the censuses for the Marine Strategy and for the regional action plan, respectively, which involved the entire coastline of the Western Mediterranean island of Sardinia. Because of the severe extent of the mass mortality, after this extensive project, we were able to find only 48 fan mussels on the western coast of the island (see Figure 2 and Table 1 for details on sampling locations and Table S1 in supplemental materials for morphometries). In particular, we collected in situ small fragments of the mantle tissue from 46 of these individuals, which were still alive at the moment of sampling, by using a non-lethal and minimally invasive technique [10] approved by the Italian "Istituto Superiore per la Protezione e la Ricerca Ambientale (ISPRA)" and "Ministero dell'Ambiente e della Tutela del Territorio e del Mare". Among the 46 live specimens of $P$. nobilis that were collected, 21 exhibited the signs of the disease and 25 did not. During the sampling collection of mantle tissue fragments, animals were classified as apparently sick when the general signs of the disease were found. In addition, tissues from four different organs (i.e., mantle, gills, digestive gland, and adductor muscle) were also collected from the whole body of two individuals from the north-west coast of Sardinia after their death. These two individuals were not classified as sick because during the census activity (occurred a few days before the sampling collection) they showed the lack of any signs of disease. The same non-lethal sampling technique was used to collect mantle samples from two individuals of the congeneric species $P$. rudis from the north-west coast of Sardinia (see Figure 1 and Table 1 for details); these individuals were classified as asymptomatic after the valve closure test.

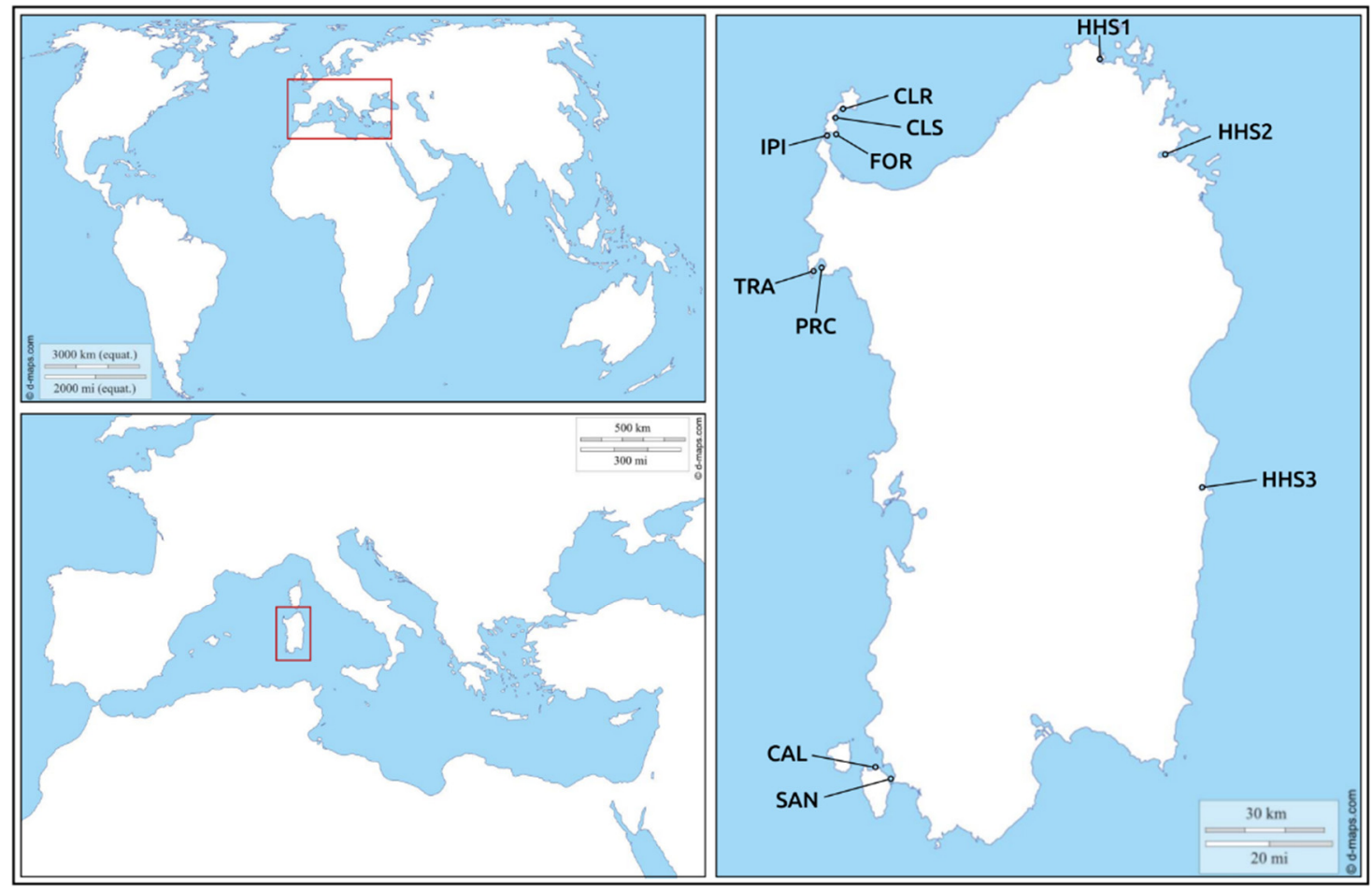

Figure 2. Sampling sites of Pinna nobilis, Pinna rudis, and heterologous host species (HHS) throughout the coast of Sardinia Island. Sampling site codes are reported in Table 1. In the site IPI, we collected Pinna nobilis and Pinna rudis. HHS1: Mytilus galloprovincialis from Olbia; HHS2 Ruditapes decussatus from Porto Pozzo; HHS3: Ruditapes decussatus from Tortolì. The maps used are available at the site: https://d-maps.com/index.php?. 
Table 1. Sampling localities for the individuals of Pinna nobilis (PN) and Pinna rudis (PR). For each sample, the presence of the signs of disease (SD), the final status of survival (FS) indicated as alive (A) or dead (D), and detection of potential etiological agents in tissues are indicated. MPA: Marine Protected Areas. Code: sampling sites code.

\begin{tabular}{|c|c|c|c|c|c|c|c|c|}
\hline Sample_ID & Locality & Code & Coordinates & SD & FS & H. pinnae & Mycobacterium spp. & Vibrio spp. \\
\hline PN1 & \multirow{4}{*}{ Sant'Antioco } & \multirow{4}{*}{ SAN } & \multirow{4}{*}{$\begin{array}{c}39^{\circ} 03^{\prime} 49.2^{\prime \prime} \mathrm{N} \\
8^{\circ} 27^{\prime} 47.6^{\prime \prime} \mathrm{E}\end{array}$} & $\mathrm{NO}$ & $\mathrm{D}$ & YES & $\mathrm{NO}$ & $\mathrm{NO}$ \\
\hline PN2 & & & & NO & $\mathrm{D}$ & YES & NO & NO \\
\hline PN3 & & & & NO & $\mathrm{D}$ & $\mathrm{NO}$ & NO & NO \\
\hline PN4 & & & & NO & $\mathrm{D}$ & $\mathrm{NO}$ & NO & NO \\
\hline PN5 & \multirow{13}{*}{ Calasetta-Cussorgia } & \multirow{13}{*}{ CAL } & \multirow{13}{*}{$\begin{array}{c}39^{\circ} 06^{\prime} 27.7^{\prime \prime} \mathrm{N} \\
8^{\circ} 23^{\prime} 54.8^{\prime \prime} \mathrm{E}\end{array}$} & NO & $\mathrm{D}$ & YES & $\mathrm{NO}$ & NO \\
\hline PN6 & & & & YES & $\mathrm{D}$ & YES & NO & NO \\
\hline PN7 & & & & NO & $\mathrm{D}$ & $\mathrm{NO}$ & NO & NO \\
\hline PN8 & & & & NO & $\mathrm{D}$ & NO & NO & NO \\
\hline PN9 & & & & NO & $\mathrm{D}$ & NO & NO & NO \\
\hline PN10 & & & & YES & $\mathrm{D}$ & NO & NO & NO \\
\hline PN11 & & & & YES & $\mathrm{D}$ & NO & NO & NO \\
\hline PN12 & & & & NO & $\mathrm{D}$ & NO & NO & NO \\
\hline PN13 & & & & NO & $\mathrm{D}$ & NO & NO & NO \\
\hline PN14 & & & & NO & $\mathrm{D}$ & $\mathrm{NO}$ & NO & NO \\
\hline PN15 & & & & NO & $\mathrm{D}$ & NO & NO & NO \\
\hline PN16 & & & & NO & $\mathrm{D}$ & NO & NO & NO \\
\hline PN17 & & & & NO & $\mathrm{D}$ & YES & NO & NO \\
\hline PN18 & \multirow{2}{*}{$\begin{array}{c}\text { Tramariglio-MPA Capo } \\
\text { Caccia Isola Piana }\end{array}$} & \multirow[b]{2}{*}{ TRA } & \multirow{2}{*}{$\begin{array}{c}40^{\circ} 35^{\prime} 23.6^{\prime \prime} \mathrm{N} \\
8^{\circ} 10^{\prime} 12.4^{\prime \prime} \mathrm{E}\end{array}$} & $\mathrm{NO}$ & $\mathrm{D}$ & YES & $\mathrm{NO}$ & $\mathrm{NO}$ \\
\hline PN19 & & & & NO & $\mathrm{D}$ & $\mathrm{NO}$ & YES & NO \\
\hline PN20 & $\begin{array}{c}\text { Porto Conte-MPA Capo } \\
\text { Caccia Isola Piana } \\
\end{array}$ & PRC & $\begin{array}{c}40^{\circ} 35^{\prime} 46.7^{\prime \prime} \mathrm{N} \\
8^{\circ} 12^{\prime} 58.1^{\prime \prime} \mathrm{E}\end{array}$ & NO & $\mathrm{A}$ & NO & $\mathrm{NO}$ & NO \\
\hline PN21 & \multirow{10}{*}{$\begin{array}{c}\text { Cala Reale-MPA Isola } \\
\text { dell'Asinara }\end{array}$} & \multirow{10}{*}{ CLR } & \multirow{10}{*}{$\begin{array}{l}41^{\circ} 03^{\prime} 47.6^{\prime \prime} \mathrm{N} \\
8^{\circ} 16^{\prime} 59.5^{\prime \prime} \mathrm{E}\end{array}$} & $\mathrm{NO}$ & $\mathrm{D}$ & $\mathrm{NO}$ & $\mathrm{NO}$ & $\mathrm{NO}$ \\
\hline PN22 & & & & YES & $\mathrm{D}$ & YES & NO & NO \\
\hline PN23 & & & & NO & $\mathrm{D}$ & YES & NO & $\mathrm{NO}$ \\
\hline PN24 & & & & YES & $\mathrm{D}$ & YES & NO & $\mathrm{NO}$ \\
\hline PN25 & & & & NO & $\mathrm{D}$ & YES & NO & NO \\
\hline PN26 & & & & $\mathrm{NO}$ & $\mathrm{D}$ & YES & NO & NO \\
\hline PN27 & & & & YES & $\mathrm{D}$ & YES & NO & NO \\
\hline PN28 & & & & YES & $\mathrm{D}$ & YES & NO & NO \\
\hline PN29 & & & & YES & $\mathrm{D}$ & YES & NO & NO \\
\hline PN30 & & & & YES & $\mathrm{D}$ & YES & NO & NO \\
\hline PN31 & \multirow{7}{*}{$\begin{array}{l}\text { Fornelli-MPA Isola } \\
\text { dell'Asinara }\end{array}$} & \multirow{7}{*}{ FOR } & \multirow{7}{*}{$\begin{array}{c}40^{\circ} 59^{\prime} 04.1^{\prime \prime} \mathrm{N} \\
8^{\circ} 15^{\prime} 06.3^{\prime \prime} \mathrm{E}\end{array}$} & YES & $\mathrm{D}$ & $\mathrm{NO}$ & $\mathrm{NO}$ & $\mathrm{NO}$ \\
\hline PN32 & & & & YES & $\mathrm{D}$ & $\mathrm{NO}$ & NO & NO \\
\hline PN33 & & & & NO & $\mathrm{D}$ & $\mathrm{NO}$ & NO & NO \\
\hline PN34 & & & & NO & $\mathrm{D}$ & YES & NO & NO \\
\hline PN35 & & & & YES & $\mathrm{D}$ & $\mathrm{NO}$ & NO & NO \\
\hline PN36 & & & & YES & $\mathrm{D}$ & YES & NO & NO \\
\hline PN37 & & & & YES & $\mathrm{D}$ & YES & NO & NO \\
\hline PN38 & \multirow{10}{*}{$\begin{array}{l}\text { Cala Scombro di } \\
\text { dentro-MPA Isola } \\
\text { dell'Asinara }\end{array}$} & \multirow{10}{*}{ CLS } & \multirow{10}{*}{$\begin{array}{c}41^{\circ} 01^{\prime} 43.5^{\prime \prime} \mathrm{N} \\
8^{\circ} 14^{\prime} 44.6^{\prime \prime} \mathrm{E}\end{array}$} & YES & $\mathrm{D}$ & YES & $\mathrm{NO}$ & NO \\
\hline PN39 & & & & YES & $\mathrm{D}$ & YES & NO & NO \\
\hline PN40 & & & & NO & $\mathrm{D}$ & YES & NO & NO \\
\hline PN41 & & & & YES & $\mathrm{D}$ & YES & NO & NO \\
\hline PN42 & & & & $\begin{array}{l}\text { YES } \\
\text { YES }\end{array}$ & $\mathrm{D}$ & YES & NO & NO \\
\hline PN43 & & & & YES & $\mathrm{D}$ & NO & NO & NO \\
\hline PN44 & & & & NO & $\mathrm{D}$ & YES & NO & NO \\
\hline PN45 & & & & NO & $\mathrm{D}$ & YES & NO & NO \\
\hline PN46 & & & & YES & $\mathrm{D}$ & YES & NO & NO \\
\hline PN47 & & & & YES & $\mathrm{D}$ & YES & NO & NO \\
\hline PN48 & & & & $\mathrm{NO}$ & $\mathrm{A}$ & $\mathrm{NO}$ & YES & NO \\
\hline PR1 & Isola Piana-MPA Isola & IPI & $40^{\circ} 58^{\prime} 42.9^{\prime \prime} \mathrm{N}$ & NO & $\mathrm{A}$ & $\mathrm{NO}$ & YES & NO \\
\hline PR2 & dell'Asinara & & $8^{\circ} 13^{\prime} 22.6^{\prime \prime} \mathrm{E}$ & NO & $\mathrm{A}$ & NO & YES & NO \\
\hline
\end{tabular}

Regarding the heterologous host bivalves, we analyzed five individuals of Mytilus galloprovincialis (Bivalvia: Mytilidae), collected during 2019 on the north-east coast of Sardinia (Olbia, SS1-40 55'09.5” N $9^{\circ} 31^{\prime} 07.8^{\prime \prime} \mathrm{E}$ ), and five individuals of Ruditapes decussatus (Bivalvia: Veneridae), collected during 2014 on the central-east coast of Sardinia (two from Porto Pozzo, SS2-41 $11^{\prime} 49.9^{\prime \prime}$ N 9 $9^{\circ} 16^{\prime} 30.4^{\prime \prime}$ E, and three from Tortoli, SS3-39 56'26.6" N 9 40'18.8” E). For these specimens, DNA was extracted from portions of the mantle and abductor muscle.

\subsection{Diagnostic Analysis}

The total genomic DNA of bivalves was isolated from a portion of mantle tissue for 46 living individuals. Furthermore, samples from tissues of four different organs (i.e., mantle, gills, digestive 
gland, and adductor muscle) were collected from the whole body of two individuals of $P$. nobilis after their death (PN1 and PN19 in Table 1). One of these two individuals (PN19) was intact and perfectly preserved: it had been spotted when it was still alive with no signs of disease; therefore, it was monitored daily by scuba divers and sampled immediately after its death to avoid tissue loss by predation and/or bacterial contamination resulting from the post mortem deterioration of tissues (see Figure 3). For this individual, molecular analyses were also performed on DNA isolated from hemolymph.

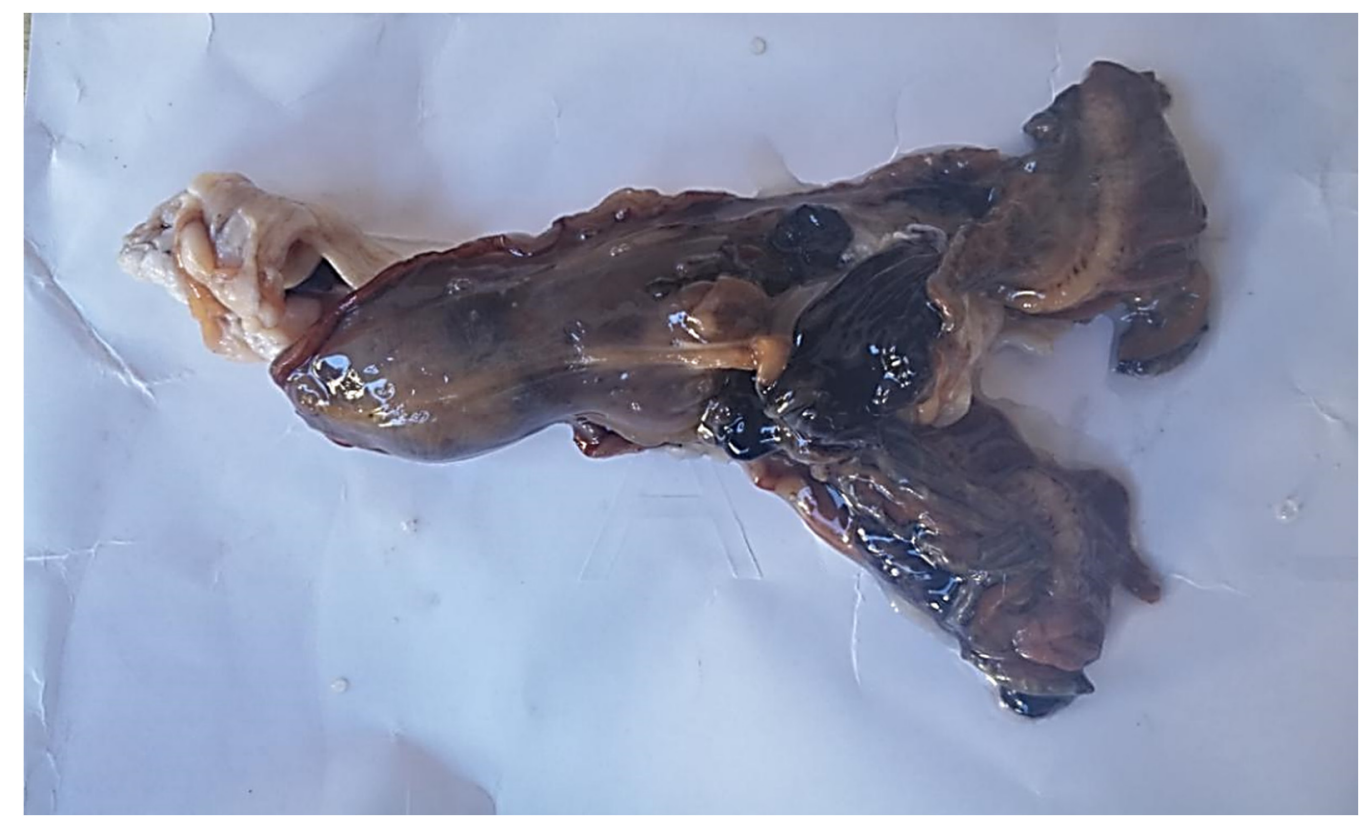

Figure 3. Whole body of the individual of Pinna nobilis that was collected immediately after dying (PN19 in Table 1).

DNA was extracted from tissue samples using the Macherey-Nagel Nucleo Spin Tissue Kit (MACHEREY-NAGEL GmbH \& Co. KG; Neumann Neander Str. 6-8 D-52355 Düren, Germany) following the supplier's instructions. All specimens were screened for pathogen DNA using standard PCR with primers targeting the protozoan nuclear $18 \mathrm{~S}$ and bacterial $16 \mathrm{~S}$ rRNA regions (see $[13,16,17]$ for primer sequences). In addition, the diagnostic PCRs were carried out also on specimens of M. galloprovincialis collected in 2019 and specimens of $R$. decussatus collected during the course of 2014 to search for evidence of present and past infections in species other than P. nobilis (used here as a potential sentinel species). In these heterologous host species, DNA was extracted from fragments of two organs, the mantle and abductor muscle. All the PCRs were carried out in a total volume of $25 \mu \mathrm{L}$. Ten nanograms of total genomic DNA on average (quantified using NanoDrop ${ }^{\mathrm{TM}}$ Lite by Thermo Scientific; 81 Wyman Street, Waltham, MA, USA) was combined with $0.6 \mu \mathrm{M}$ of each primer and one pellet of PuReTaq Ready-To-Go PCR beads (GE Healthcare; 9900 West Innovation Drive, Wauwatosa, WI, USA) containing stabilizers, Bovine Serum Albumin (BSA), deoxynucleotide triphosphates, 2.5 units of PuReTaq DNA polymerase, and reaction buffer. For each bead that was reconstituted to a $25 \mu \mathrm{L}$ final volume, the concentration of each dNTP was $200 \mu \mathrm{M}$ and $\mathrm{MgCl}_{2}$ was $1.5 \mathrm{mM}$. PCRs were performed in a GeneAmp PCR System 9700 Thermal Cycler (Applied Biosystems; 81 Wyman Street, Waltham, MA, USA) using the following program: 1 cycle of 4 min at $94{ }^{\circ} \mathrm{C}, 35$ cycles of $30 \mathrm{~s}$ at $94{ }^{\circ} \mathrm{C}, 30 \mathrm{~s}$ at $54{ }^{\circ} \mathrm{C}$ (for the $18 \mathrm{~S}$ rRNA gene) or $59^{\circ} \mathrm{C}$ (for the $16 \mathrm{~S}$ rRNA gene), and $30 \mathrm{~s}$ at $72{ }^{\circ} \mathrm{C}$. In the end, a post-treatment of $5 \mathrm{~min}$ at $72{ }^{\circ} \mathrm{C}$ and a final cooling at $4{ }^{\circ} \mathrm{C}$ were carried out. Both positive (old samples stored in our laboratory that always produce good PCR products for the primers used in the present study) and negative controls were used to test the effectiveness of the PCR protocols and confirmed the absence of possible inhibitors. In particular, the positive DNA controls we used were 
samples of Crassostrea gigas for the detection of Vibrio spp. and Haplosporidium spp. and samples of Ostrea edulis for the detection of Mycobacterium spp. Electrophoresis was carried out on 2\% agarose gels that were prepared using $1 \times$ TAE buffer (sodium boric acid, $\mathrm{pH}$ 8.2) and stained with Gel Red Nucleic Acid Stain (Biotium Inc.; 46117 Landing Parkway, Fremont, CA, USA). PCR products were purified using ExoSAP-IT (USB Corporation; 26111 Miles Rd, Cleveland, OH, USA), and both the forward and reverse strands were sequenced (using the same primers used for PCR) by an external sequencing core service (Macrogen, The Netherlands).

For diagnostic analyses of protozoans and bacteria, the absence of reaction inhibitors in the solutions of extracted DNA was verified by performing at least two PCRs for each sample with species-specific mitochondrial primers (Cytochrome c Oxidase sub. I) for P. nobilis, according to the protocol described by Sanna et al. [10,11].

The pathological diagnostic analysis was also performed on PN19, the dead individual whose body was perfectly preserved after its death (Figure 3). We excluded the second individual found dead (PN1) from this analysis because its body, although it showed no signs of tissue decay, had been partially subjected to predation by muricids, suggesting the possible early onset of the bacterial decomposition process. For PN19, four different organ tissue fragments (i.e., mantle, gills, digestive gland, and adductor muscle) were used as the matrix for the bacteriological examination. Culture tests were performed on Columbia Blood Agar (Liofilchem, Italy), Tryptic Soy Agar (TSA) with 2\% NaCl, Marine Agar (MA), and Thiosulfate-Citrate-Bile Salts-Sucrose Agar (TCBS); this last medium was used for the Vibrionaceae screen. First, $100 \mu \mathrm{L}$ of hemolymph was inoculated on each medium, followed by incubation at $22 \pm 2{ }^{\circ} \mathrm{C}$ for $72 \mathrm{~h}$. Grown colonies were identified preliminarily using Matrix-assisted laser desorption ionization time of flight (MALDI-TOF) Mass Spectrometry (MS) on a VITEK MS system (bioMérieux, Marcy-l'Étoile, Chemin de l'Orme, France). Together with the bacteriological analyses, specific culture tests were carried out to screen for non-tuberculous mycobacteria. First, $100 \mu \mathrm{L}$ of hemolymph was inoculated into Middlebrook 7H9 broth (Microbiol, Italy) and incubated at $28 \pm 1{ }^{\circ} \mathrm{C}$ for two weeks. Then, $10 \mu \mathrm{L}$ of the broth was taken with a sterile loop and used to inoculate selective media for mycobacteria, as described in detail by Varello et al. [22]. DNA was extracted from the grown colonies by boiling and freeze-thawing and subjected to a mycobacteria-specific PCR targeting a $440 \mathrm{bp}$ portion of the hsp65 gene; the reaction protocols followed those reported by Antuofermo et al. [23].

\subsection{Statistical Analysis}

All the obtained 18S and 16S sequences were used for BLAST searches in the GenBank nucleotide database (NCBI) (https://blast.ncbi.nlm.nih.gov/Blast.cgi?CMD=Web\&PAGETYPE=BLASTHome) to search for significant matches (if any) with sequences already reported. The sequences obtained in the present study were then aligned with sequences from conspecifics and congenerics from other localities and hosts downloaded from GenBank (see Figure 4 for accession numbers) using the Q-INS-I algorithm implemented in Mafft 7.187 [24].

Regarding the H. pinnae $18 \mathrm{~S}$ marker, we obtained 31 (27 from P. nobilis and 4 from the heterologous host species) identical 1205-bp-long sequences (only one sequence was 1216 bp long).

Regarding the 16S molecular marker, we obtained one Rhodococcus sp. sequence from PN19 (P. nobilis) and four Mycobacterium sp. sequences from the individuals PN19, PN48 (P. nobilis), and PR1, PR2 (P. rudis). To include the newly obtained sequences in a worldwide context, we first produced a large dataset that contained all of the sequences of the genera Mycobacterium and Rhodococcus available in GenBank for this bacterial region (i.e., 1,200,135 for Mycobacterium spp. and 84,544 for Rhodococcus spp.). We then obtained a final version of the dataset after performing several steps of filtering, which took into consideration genetic distances, query cover, identity, and isolation. These filtering steps allowed us to make the dataset as representative and informative as possible for all the sequences considered. The 16S definitive dataset contained 65 sequences with a size of $794 \mathrm{bp}, 33$ of which belonged to Mycobacterium spp. and 31 to Rhodococcus spp.; a sequence of Staphylococcus aureus was used as an 
outgroup. Then, tests for the phylogenetic signal were performed using TreePuzzle [25] to verify the dataset reliability [26].

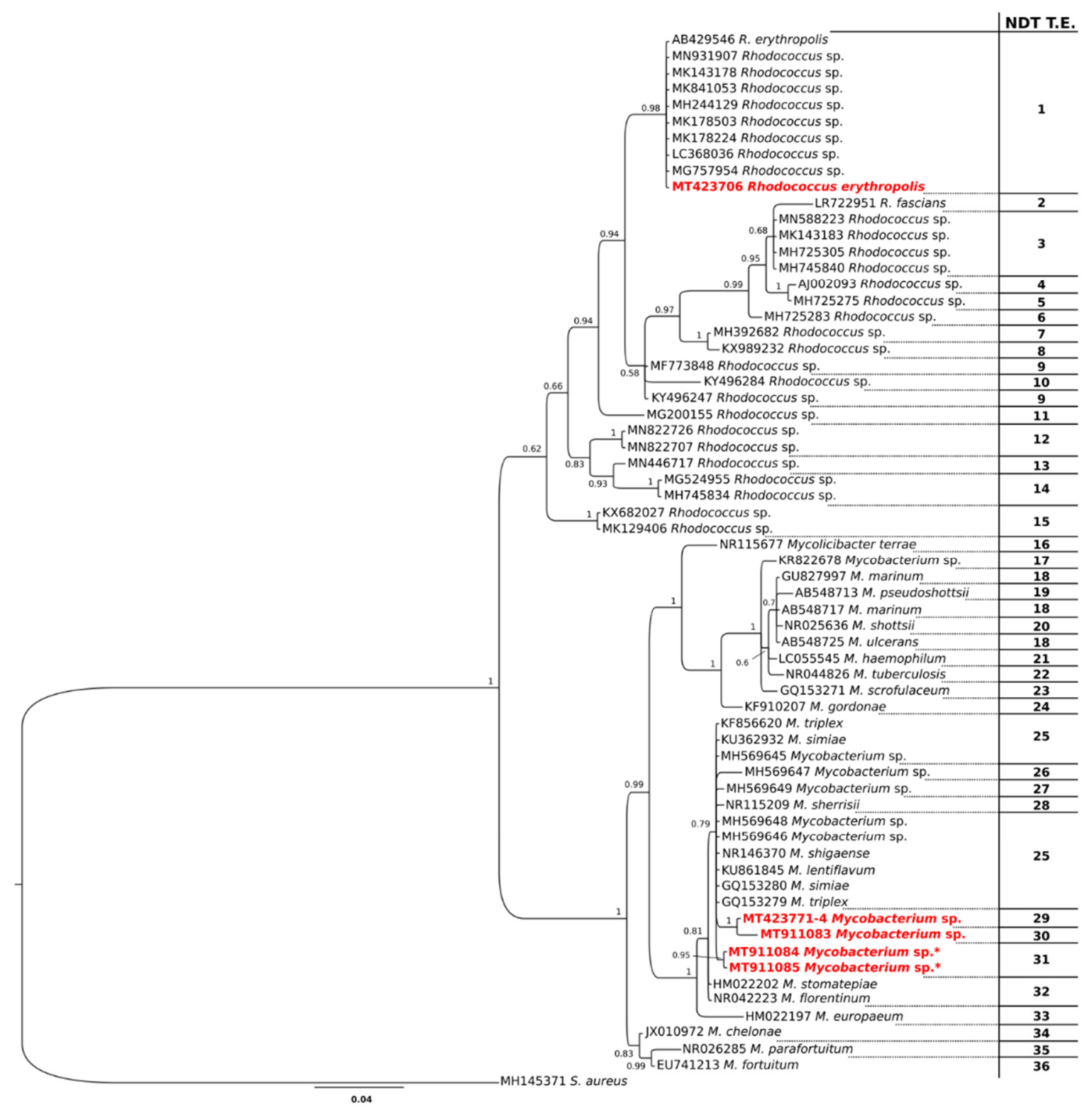

Figure 4. Bayesian phylogenetic tree showing the relationships among bacteria taxa. The column on the right (nucleotide divergence threshold (NDT T.E.) indicates the taxonomic entities found by the NDT method. The sequences obtained in the present study are reported in red font. The asterisk indicates the sequences of bacteria isolated from individuals of Pinna rudis.

Taxonomic assessments and phylogenetic relationships among the investigated taxa were verified using the Bayesian Inference method, which was performed using the software MrBayes 3.2.6 [27], following the method described by Scarpa et al. [28]. The runs were carried out at the Cipres Phylogenetic Portal [29] and checked for the convergence following the procedure described by Ronquist et al. [27] and Gelman and Rubin [30]. The phylogenetic tree was visualized and edited using FigTree 1.4.0 (available at http://tree.bio.ed.ac.uk/software/figtree/). To corroborate the taxonomic assessment obtained according to the phylogenetic species concept, a species delimitation method was also performed using the nucleotide divergence threshold (NDT) using a script [31] written in the R statistical environment, implementing the evolutionary rates of Duchêne et al. [32]. 


\section{Results}

\subsection{Protozoa}

PCRs were positive for $H$. pinnae in 27 out of the 48 individuals of $P$. nobilis analyzed (56.3\%), and this protozoan was present in $71.4 \%$ of individuals with signs of disease and in $44.4 \%$ of individuals without signs of disease (see Table 1 for details). PCRs were considered negative when two attempts to amplify the same sample did not produce any electrophoretic bands. A large number of infected fan mussels made it possible to test for differences between the occurrence of the signs of disease (the data were collected for all individuals found still living) and the presence of H. pinnae in the tissues of individuals using the Pearson's Chi-squared test (also with Yates' continuity correction). The individuals with the signs of disease were 21 (15 of which were positive and six negative for H. pinnae), while individuals with no signs of disease were 27 (12 of which were positive and 15 negative for $H$. pinnae). The results of this test indicated that the Chi-square statistic amounts to $3.5(p=0.06)$ and the Chi-square statistic with Yates' correction (which is known to be over-cautious for avoiding a type 1 error) amounts to $2.5(p=0.11)$. In both cases, taking into account that differences were considered statistically significant at $p<0.05$, no association between the occurrence of the signs of disease and the presence of the $H$. pinnae was detected. Notably, even if the presence of $H$. pinnae was found in only $56.3 \%$ of all the analyzed fan mussels, all these individuals but two died in the meanwhile (see Table 1). Accordingly, the live status of fan mussels (dead vs. alive) was not used as a variable for statistical analyses. It should be pointed out that the lack of environmental data (e.g., $\mathrm{pH}$, salinity, and temperature) might represent a source of bias in this type of analysis.

All of the 18S rRNA sequences we obtained for H. pinnae, both from P. nobilis (MT431961-MT431987) and the heterologous host species (MT585819-MT585822), were identical among each other and exactly matched one of the 11 low-variable 18S rRNA sequences previously reported for $H$. pinnae isolated from $P$. nobilis [12-14,33,34], thus preventing further phylogenetic inferences.

Regarding the heterologous host organisms, PCRs for $H$. pinnae were positive in three specimens of R. decussatus (sampled in 2014) and one specimen of M. galloprovincialis (sampled in 2019). These results indicated that these heterologous host species can be considered as sentinel species, as they were hosts for the same pathogens as $P$. nobilis. Accordingly, hereafter, we refer to them as sentinel species. The PCRs for $H$. pinnae were negative for $P$. rudis (see Table 1).

The DNA samples for which PCRs of Cytochrome c Oxidase sub. I on P. nobilis, aimed to verify the lack of inhibitors, did not give bands to the electrophoresis would be considered as contaminated by inhibitors and for this reason unsuitable for these diagnostic tests. Notably, all the DNA samples analyzed in the present study were found PCR inhibitors-free.

\subsection{Bacteria}

In accordance with our Ministerial authorization (approved by ISPRA and the Italian 'Ministero dell' Ambiente e della Tutela del Territorio e del Mare-Italy'), which allows the collection of only a small piece of the mantle from individuals in a non-lethal manner regardless of their health condition, PN19 was the only sample on which bacteriological examinations were performed because it was found just after it died, perfectly preserved, and without signs of decay (Figure 3). All of the other samples were tested for the presence of bacteria using only the PCR technique. Bacteriological examinations performed on the whole body of the individual PN19 revealed that colonies only formed on Columbia Blood agar. All the isolates were identified as Rhodococcus erythropolis using MALDI-TOF MS. Consistently, a 16S rRNA 794-bp-long sequence was obtained (GenBank accession number: MT423706) from a culture obtained from hemolymph that showed $99.87 \%$ identity with Rhodococcus erythropolis after BLAST analysis. Notably, in the bacteriological examination for the sample PN19, the non-tuberculous mycobacteria screening was negative (no colonies were isolated on selective media). 
PCRs of the $16 \mathrm{~S}$ rRNA fragment performed with DNA extracted from tissues were negative for the presence of bacteria in 46 out of the 48 fan mussel individuals. The only exceptions were the individuals PN19 (from the north-west coast of Sardinia) and PN48 (from the north coast of Sardinia), which were positive for a species of Mycobacterium. Interestingly, positive PCR results for bacterial $16 \mathrm{~S}$ rRNA were also obtained for the P. rudis individuals collected along the coasts of Asinara.

As already reported above, also in this case, the DNA samples for which PCRs, aimed to verify the lack of inhibitors, did not give bands to the electrophoresis would be considered as contaminated by inhibitors and for this reason unsuitable for diagnostic tests. Notably, all the DNA samples analyzed in the present study were found PCR inhibitors-free.

BLAST analysis revealed that the 16S rRNA Mycobacterium sequence that we obtained for the P. nobilis individual PN19 (GenBank accession numbers for identical sequences obtained from the four different organ tissues: MT423771-MT423774) showed a 99.75\% identity with Mycobacterium lentiflavum, M. shigaense, M. simiae, M. triplex, and several Mycobacterium sp., including the uncultured sequences reported by Carella et al. [16]. The sequences obtained for the individual PN48 (GenBank accession number: MT791083) and the two individuals of P. rudis (GenBank accession numbers: MT791084-5) showed a 99.62\% and 99.87\% identity, respectively, with Mycobacterium lentiflavum, M. simiae, M. shigaense, M. triplex, and several Mycobacterium sp., including the uncultured sequences reported by Carella et al. [16].

No positive PCRs were obtained for Vibrio spp. in the present study (see Table 1), possibly because of the methodology we used for the detection. Our Mycobacterium and Rhodococcus sequences were included in a dataset containing congenerics whose sequences were available in GenBank and selected according to the method described above (see the Materials and Methods section).

The likelihood-mapping analysis (see Figure S1 in supplementary) indicated that there was a very strong phylogenetic signal, with $4.0 \%$ of points in the network-like area, indicating that our data were reliable for phylogenetic and taxonomic inferences [26]. Analyses of the phylogenetic trees (Figure 4) revealed two main clades, with a fully supported dichotomy, representative of the genera Rhodococcus and Mycobacterium, respectively. The sequences of Mycobacterium sp. obtained in the present study were included in a well-supported clade containing $M$. lentiflavum, $M$. triplex, $M$. simiae, $M$. sherrisii, M. shigaense, and the Mycobacterium sp. sequences isolated from individuals of $P$. nobilis from the Tyrrhenian coastline of Italy [16]. Moreover, the sequence that we obtained for Rhodococcus was included in a highly supported clade containing the sequences of $R$. erythropolis and several sequences belonging to the genus without specific taxonomic attribution.

Notably, the species delimitation analyses, which highlighted a total of 37 taxonomic entities, revealed that the sequences of Mycobacterium obtained in the present study belong to three distinct taxonomic entities, which do not include the other sequences of the genus included in the dataset (see Figure 4 for details). On the contrary, the sequence of Rhodococcus erythropolis isolated in the present study belongs to the same taxonomic entity that includes the sequences of $R$. erythropolis from GenBank (Figure 4).

\section{Discussion}

Such mass mortality, as dramatic as the one that $P$. nobilis is experiencing, represents an unprecedented phenomenon that has never been recorded also for other species of pinnids [12]. The only quite similar occurrence within Pinnidae was reported for Atrina pectinata in Japan during late spring and summer in 2003 and 2004 [35], even if with limited risk for the persistence of the species. In that case, the search for etiological agents provided crucial information to understand the phenomenon. The wide distribution range of A. pectinata may explain its good recovery: the extensive spreading of this species into the Indo-Pacific may have helped to prevent an irreversible effect on its conservation status, although the local extinction of some Japanese populations probably caused a general loss of genetic variability. On the contrary, the chance for a quick recovery of $P$. nobilis following the present mass mortality event could be hindered by its narrow range of distribution, 
and aggregative patterns of populations [36], as well as the semi-enclosed nature of the Mediterranean Sea [37], which allows pathogens to remain within the basin for a long time. The extinction of P. nobilis would severely damage Mediterranean biodiversity, and its effect would extend beyond the loss of a single species. Indeed, P. nobilis is considered a key species (habitat former) because it provides a hard substrate in areas with soft bottoms, increasing habitat complexity by providing a surface for other benthic species (algae, sponges, bivalves, polychaetes, etc.) [38,39]. In addition, the fan mussel is a host for symbionts such as the crustaceans Pontonia pinnophylax and Nepinnotheres pinnotheres [40], and it is also predated by other species (e.g., the cephalopod Octopus vulgaris), playing a key role in the trophic web [41]. This study sheds further light on the intricate patterns that are involved in the mass mortality of P. nobilis in the Western Mediterranean. Even though our analyses were limited to a small number of samples because of the extremely high mortality rates recorded for P. nobilis all along the coasts of Sardinia, the new information we obtained will help to bring us closer to fully understanding the causes of this phenomenon. A complete understanding of the causes of this mass mortality is crucial for developing a successful recovery plan for the species, also considering that its high potential for larval dispersal may favor a rapid recolonization across the Mediterranean basins. Indeed, before mass mortality, P. nobilis has been shown to exhibit overall genetic uniformity across the Mediterranean, with a slight genetic break at the level of the Siculo-Tunisian Straits [10], such as other Mediterranean mollusks (see, e.g., [42-44]).

Protozoans are typically the first putative pathogens investigated in cases of mass mortality involving bivalves. In particular, haplosporidian endoparasites have been the cause of mortality events for many bivalve populations [45], and they have been extensively studied, especially in mollusks of high commercial interest [46-51]. Indeed, H. pinnae was initially considered as the potential promoter of the mass mortality of $P$. nobilis $[7,8]$ because it was the first pathogen found in large quantities on dead and moribund fan mussel individuals [12-15] and because it has been considered to be a specific-species protozoan of $P$. nobilis.

Notably, our results indicated that $H$. pinnae is not species-specific for the fan mussel, as was initially hypothesized [13], as it was found in samples of M. galloprovincialis and R. decussatus, the last of which were collected in 2014. This finding indicates that this protozoan was present in the Mediterranean at least two years before the beginning of the P. nobilis mass mortality event (since 2016) [12-15] and sheds doubts on the hypothesis that $H$. pinnae played a pivotal role in the mass mortality of fan mussels.

Moreover, in accordance with what has already been suggested by Carella et al. [19] (and references therein) for individuals from the northern coast of Spain and by Lattos et al. [33] for Greek populations of the Thermaikos Gulf, our study further supports a hypothesis that is gaining popularity that P. nobilis mass mortality is not linked exclusively to infection by the protozoan H. pinnae [16-19,33] (and references therein). In this context, we detected no association between the occurrence of the typical signs of disease responsible for the death of individuals of $P$. nobilis and the presence of $H$. pinnae in their tissues. We found the occurrence of $H$. pinnae in only just over half of the analyzed fan mussels and in just under half of the living individuals that did not show the signs of illness. In particular, among specimens that resulted positive for the presence of $H$. pinnae $(\mathrm{n}=27)$, only $55.6 \%$ showed the typical signs associated with the illness, while $44.4 \%$ were apparently healthy. However, it should be noted that the tissue analyzed (a $15 \mathrm{mg}$ portion of muscle from the mantle) is not the target tissue of $H$. pinnae, which has been shown to proliferate in digestive glands, and a possible low concentration of DNA in the mantle tissue may have produced some false-negative results [34]. Unfortunately, access to the target organ with a non-invasive approach is not safely possible in alive specimens. Indeed, in the respect of this protected species that is on the brink of extinction, for which sampling of entire individuals when alive are strictly forbidden, and in accordance with our Ministerial authorization (approved by ISPRA and the Italian 'Ministero dell'Ambiente e della Tutela del Territorio e del Mare'), we received the permission to collect only a small piece of the mantle from alive individuals, in order not to cause lethal damages, which should be avoided particularly in this crucial moment for the survival of $P$. nobilis. 
Nonetheless, it should be noted that the diagnostic PCRs performed for the two specimens found dead (PN1 and PN19) did not return discrepancies among results from the four different organs. Indeed, we found accordance either for positivity (PN1) or negativity (PN19) to H. pinnae in each one of the tested tissues (i.e., mantle, gills, digestive gland, and adductor muscle).

In such a context, future analyses performed by using RT-PCR will allow us to detect even ephemeral concentration of pathogenic DNA when analyzing a small portion of mantle tissue.

Our findings are also consistent with those obtained in wild [16] and stabled [17] individuals of P. nobilis, which indicated that fan mussels showed the typical traits of the disease associated with the mass mortality without the presence of $H$. pinnae. This evidence further demonstrates the lack of a clear connection between this protozoan and the death of $P$. nobilis. Hence, our results, together with those recently reported $[19,33]$, increasingly support a multifaceted scenario that is more complex than expected, in which the occurrence of a multifactorial disease may be the actual cause for the mass mortality event of $P$. nobilis - namely, the disease is not conveyed by a host species-specific pathogen (as was initially concluded regarding $H$. pinnae) but rather by multiple co-occurring pathogens. In this context, additional environmental data would help to corroborate these results or at least clarify if there is also an abiotic component involved in the mass mortality of fan mussels. Unfortunately, these data were not available for each sampling site during the present study, thus preventing to perform these types of analyses.

Regarding the Sardinian area, it is interesting to note that, for two out of three Sardinian individuals sampled in the central-western coast of the island (Oristano), Carella et al. [19] reported the presence of a pathogenic dinoflagellate, Perkinsus sp., associated with Mycobacterium sp. and H. pinnae. In the present study we detected Rhodococcus erythropolis (in cultures from hemolymph) associated with Mycobacterium sp. in one individual of $P$. nobilis from the northern coast (sample PN19), which represents the first report of a bacterium species in fan mussels other than Mycobacterium spp. and Vibrio spp. This finding supports the co-occurrence in P. nobilis of pathogenic taxa other than those already described $[14,16,17]$. Moreover, recent results indicate that the mass mortality of $P$. nobilis is likely not just the result of an infection by Mycobacterium spp. and H. pinnae [14,16]. For this reason, additional studies should be performed to evaluate the roles of the pathogens recently identified, such as R. erythropolis and Perkinsus sp., in the fan mussel mass mortality. Considering that R. erythropolis has been found only in one sample of $P$. nobilis, it is currently difficult to determine its role in the mass mortality event. Indeed, species of Rhodococcus are known to have remarkably diverse catabolic abilities [52], but several strains are also able to produce antibiotic type molecules [53]. For instance, Kitagawa and Tamura [54] found antibacterial properties in 80 different strains of Rhodococcus, which produced at least three different inhibitory compounds, and 14 of these were taxonomically identified as R. erythropolis [54]. These inhibitory molecules show a spectrum of activity against several species of Rhodococcus and closely related genera [53]. In this context, the occurrence of R. erythropolis could not necessarily be deleterious for the host.

Accordingly, the hypothesis that $R$. erythropolis might provide protection, having a 'probiotic effect' on other potential pathogens, cannot be ignored. On the other hand, it must be considered that R. erythropolis has been reported to cause illness in Atlantic salmon, Salmo salar [55], and in our study, it was found in a dead individual. Thus, based on the current data, we cannot rule out that R. erythropolis might be involved, together with other pathogens, in the mass mortality of $P$. nobilis.

Notably, no positive PCRs were obtained for Vibrio spp. in the present study, indicating the possible absence of these bacteria among Sardinian fan mussels and agreeing with the trend already reported for Apulian populations [14]. Our phylogenetic analysis showed that the sequences of Mycobacterium sp. we obtained are very close to those of species of mycobacteria that are common in marine/aquatic hosts, such as M. lentiflavum, M. triplex, M. simiae, M. sherrisii, and M. shigaense, and the BLAST analysis revealed high percentages of similarity with several already known species of Mycobacterium. The species delimitation results showed that the Mycobacterium spp. found in our samples belong to three taxonomic entities that have never been described to date and were reported 
for the first time in Sardinian samples. This finding is consistent with Carella et al. [19] (and references therein) who also reported the likely occurrence of a new species of mycobacteria infecting P. nobilis, which was closely related to M. triplex and M. sherrisii. This large number of Mycobacterium species found to date in the fan mussel, as well as the new possible pathogens that are gradually being discovered, suggests that the overall role of mycobacteria in the mass mortality event, as well as that of H. pinnae, should be re-evaluated. This scenario is also supported by the discrepancies in the infection levels between Sardinian individuals analyzed in the present study ( 2 out of 48 individuals, about $4 \%$ ) and individuals from the north-west coast of Spain and southern coast of the Tyrrhenian Sea, for which Carella et al. [16,19] reported levels of $50 \%$ and slightly less than $100 \%$, respectively.

A species of Mycobacterium was also identified by PCR in individuals of P. rudis that were still alive (last checked on May 2020) and did not show the signs of the disease at the time of sampling or during periodic checks. This finding suggests the possible presence of several species of Mycobacterium in the aquatic environment, although, as in this case, they might not play a pathogenic role.

\section{Conclusions}

Our results support the occurrence of a multifactorial disease as a possible explanation for the mass mortality of $P$. nobilis, as Mycobacterium spp. and $H$. pinnae are not always associated with the illness. Indeed, the lack of $H$. pinnae in many specimens with signs of disease, together with its presence in living individuals with no signs, further suggests that $H$. pinnae cannot be the only cause of this phenomenon.

In addition, our results from analyses of sentinel species indicate that $H$. pinnae is not species-specific for P. nobilis, as it has been present in the Mediterranean in other bivalves at least since 2014, questioning the proposed role of this protozoan in the fan mussel mass mortality event. Future studies should aim to corroborate the molecular results while also using an environmental parameter-based approach.

Consistently, species of Mycobacterium were also found to be present in healthy individuals of P. nobilis and P. rudis, suggesting that the presence of mycobacteria may be not linked to the causes of the mass mortality, which is likely because these species have been shown to be common etiological agents in the marine environment. In this context, the occurrence of $R$. erythropolis represents the first report of this bacteria species in $P$. nobilis, providing a new candidate for further investigations to clarify its role (if any) in the mass mortality of fan mussels.

Currently, the causes of this phenomenon are far from being completely understood. Two main factors hinder the clarification of the causes: (i) the lack of a large number of fan mussels to survey and (ii) the impossibility to analyze a proper number of fan mussel entire soft bodies due to the extreme rarity and the levels of total protection to which P. nobilis is subjected. In this context, the use of sentinel species may play a pivotal role in identifying the etiological agents involved in the mass mortality, and when combined with more powerful diagnostic methods (such as real-time PCR), they might help overcome the problems related to working on small portions of mantle tissue obtained with a non-lethal sampling method.

Supplementary Materials: The following tables and figures are available online at http://www.mdpi.com/20751729/10/10/238/s1, Table S1: Shell morphometric measurements for the individuals of Pinna nobilis (PN) and Pinna rudis (PR) that were analyzed in the present study, Figure S1: Likelihood map depicting the distribution of dots $P$, where P represents the likelihoods of the three possible unrooted trees for a set of four sequences $[25,26]$. Central area represents a star-like signal (phylogenetic noise). The value above the triangle represents the percentage of dots in the network-like area. A percentage lower than $20-30 \%$ indicates that the dataset is reliable for phylogenetic and taxonomic analyses with a good phylogenetic signal [26].

Author Contributions: F.S.: research conceiving, sample design, specimen's collection, data collection, statistical and phylogenetic analysis, data interpretation, writing original draft, reviewing, and editing. D.S.: research conceiving, methodology design, molecular analysis, data interpretation, writing original draft, reviewing, and editing. I.A.: data collection, molecular analysis, and editing. S.H.: molecular analysis. D.M. and F.C.: molecular and pathological diagnostic analysis. P.C.: data interpretation and reviewing. E.A.: advising. F.A., T.S., M.A.M., P.A., L.A.S., M.P., S.P. (Simone Peletto), and V.G.: final reviewing. S.P. (Stefania Pinna), D.G., D.C., V.P., G.E. and N.C.: specimen's collection and editing. M.C.: research conceiving, sample design, data interpretation, 
writing original draft, reviewing, and editing. All authors have read and agreed to the published version of the manuscript.

Funding: This research was financed by Regione Autonoma della Sardegna-RAS by means of the project "Piano di Azione Regionale per la conservazione di Pinna nobilis" (Allegato alla Delib.G.R. n. 61/39 del 18.12.2018).

Acknowledgments: We are indebted to the entire staff of the Sardinian Marine Protected Areas involved in the RAS project. We would like to especially thank all the volunteers who participated in the International Marine Centre (IMC) citizen science project.

Conflicts of Interest: The authors and the founders declare no conflict of interest.

\section{References}

1. Schultz, P.; Huber, M. Revision of the Worldwide Recent Pinnidae and some Remarks on Fossil European Pinnidae. Acta Conch. 2013, 13, 1-164.

2. Rouanet, E.; Trigos, S.; Vicente, N. From youth to death of old age: The 50-year story of a Pinna nobilis fan mussel population at Port-Cros Island (Port-Cros National Park, Provence, Mediterranean Sea). Sci. Rep. Port-Cros Natl. Park 2015, 29, 209-222.

3. Zavodnik, D.; Hrs-Brenko, M.; Legac, M. Synopsis of the fan shell Pinna nobilis L. in the eastern Adriatic Sea. In Les Espèces Marines à Protéger en Méditerranée; Boudouresque, C.F., Avon, M., Gravez, V., Eds.; GIS Posidonie: Marseille, France, 1991; pp. 169-178.

4. Basso, L.; Vázquez-Luis, M.; García-March, J.R.; Deudero, S.; Alvarez, E.; Vicente, N.; Duarte, C.M.; Hendriks, I.E. The Pen Shell, Pinna nobilis. Adv. Mar. Biol. 2015, 71, 109-160. [CrossRef]

5. Trigos, S.; Vicente, N.; Prado, P.; Espinós, F.J. Adult spawning and early larval development of the endangered bivalve Pinna nobilis. Aquaculture 2018, 483, 102-110. [CrossRef]

6. Butler, A.; Vicente, N.; Gaulejac, B. Ecology of the pterioid bivalves Pinna bicolor Gmelin and Pinna nobilis L. Mar. Life 1993, 3, 37-45.

7. Katsanevakis, S. Population ecology of the endangered fan mussel Pinna nobilis in a marine lake. Endanger. Species Res. 2004, 1, 51-59. [CrossRef]

8. Rabaoui, L.; Tlig-Zouari, S.; Katsanevakis, S.; Hassine, O.K.B. Modelling population density of Pinna nobilis (Bivalvia) on the eastern and southeastern coast of Tunisia. J. Molluscan Stud. 2010, 76, 340-347. [CrossRef]

9. Vázquez-Luis, M.; Borg, J.A.; Morell, C.; Banach-Esteve, G.; Deudero, S. Influence of boat anchoring on Pinna nobilis: A field experiment using mimic units. Mar. Freshw. Res. 2015, 66, 786-794. [CrossRef]

10. Sanna, D.; Cossu, P.; Dedola, G.L.; Scarpa, F.; Maltagliati, F.; Castelli, A.; Franzoi, P.; Lai, T.; Cristo, B.; Curini-Galletti, M.; et al. Mitochondrial DNA Reveals Genetic Structuring of Pinna nobilis across the Mediterranean Sea. PLoS ONE 2013, 8, e67372. [CrossRef]

11. Sanna, D.; Dedola, G.; Scarpa, F.; Lai, T.; Cossu, P.; Curini-Galletti, M.; Francalacci, P.; Casu, M. New mitochondrial and nuclear primers for the Mediterranean marine bivalve Pinna nobilis. Mediterr. Mar. Sci. 2014, 15, 416. [CrossRef]

12. Vázquez-Luis, M.; Álvarez, E.; Barrajón, A.; García-March, J.R.; Grau, A.; Hendriks, I.E.; Jiménez, S.; Kersting, D.K.; Moreno, D.; Pérez, M.; et al. S.O.S. Pinna nobilis: A Mass Mortality Event in Western Mediterranean Sea. Front. Mar. Sci. 2017, 4, 220. [CrossRef]

13. Catanese, G.; Grau, A.; Valencia, J.; García-March, J.R.; Vazquez-Luis, M.; Alvarez, E.; Deudero, S.; Darriba, S.; Carballal, M.J.; Villalba, A. Haplosporidium pinnae sp. nov., a haplosporidan parasite associated with mass mortalities of the fan mussel, Pinna nobilis, in the Western Mediterranean Sea. J. Invertebr. Pathol. 2018, 157, 9-24. [CrossRef]

14. Panarese, R.; Tedesco, P.; Chimienti, G.; Latrofa, M.S.; Quaglio, F.; Passantino, G.; Buonavoglia, C.; Gustinelli, A.; Tursi, A.; Otranto, D. Haplosporidium pinnae associated with mass mortality in endangered Pinna nobilis (Linnaeus 1758) fan mussels. J. Invertebr. Pathol. 2019, 164, 32-37. [CrossRef]

15. Katsanevakis, S. The cryptogenic parasite Haplosporidium pinnae invades the Aegean Sea and causes the collapse of Pinna nobilis populations. Aquat. Invasions 2019, 14, 150-164. [CrossRef]

16. Carella, F.; Aceto, S.; Pollaro, F.; Miccio, A.; Iaria, C.; Carrasco, N.; Prado, P.; De Vico, G. A mycobacterial disease is associated with the silent mass mortality of the pen shell Pinna nobilis along the Tyrrhenian coastline of Italy. Sci. Rep. 2019, 9, 2725. [CrossRef] [PubMed] 
17. Prado, P.; Carrasco, N.; Catanese, G.; Grau, A.; Cabanes, P.; Carella, F.; García-March, J.R.; Tena, J.; Roque, A.; Bertomeu, E.; et al. Presence of Vibrio mediterranei associated to major mortality in stabled individuals of Pinna nobilis L. Aquaculture 2020, 519, 734899. [CrossRef]

18. Andree, K.B.; Carrasco, N.; Carella, F.; Furones, D.; Prado, P. Vibrio mediterranei, a Potential Emerging Pathogen of Marine Fauna: Investigation of pathogenicity using a bacterial challenge in Pinna nobilis and development of a species-specific PCR. J. Appl. Microbiol. 2020. [CrossRef]

19. Carella, F.; Antuofermo, E.; Farina, S.; Salati, F.; Mandas, D.; Prado, P.; Panarese, R.; Marino, F.; Fiocchi, E.; Pretto, T.; et al. In the wake of the ongoing mass mortality events: Co-occurrence of Mycobacterium, Haplosporidium and other pathogens in Pinna nobilis collected in Italy and Spain (Mediterranean Sea). Front. Mar. Sci. 2020, 7. [CrossRef]

20. Scarpa, F.; Marcia, P.; Cossu, P.; Lai, T.; Sechi, S.; Curini-Galletti, M.; Sanna, D.; Azzena, I.; Zanello, A.; Gazale, V.; et al. Marine strategy as needful tool for the management of endangered species: The study case of Pinna nobilis (Mollusca: Bivalvia). Biol. Mar. Mediterr.. in press.

21. Garrabou, J.; Coma, R.; Bensoussan, N.; Bally, M.; Chevaldonné, P.; Cigliano, M.; Diaz, D.; Harmelin, J.G.; Gambi, M.C.; Kersting, D.K.; et al. Mass mortality in Northwestern Mediterranean rocky benthic communities: Effects of the 2003 heat wave. Glob. Chang. Biol. 2009, 15, 1090-1103. [CrossRef]

22. Varello, K.; Prearo, M.; Burioli, E.A.V.; Pastorino, P.; Mugetti, D.; Meistro, S.; Righetti, M.; Bozzetta, E. Mycobacterium fortuitum infection in silver arowana (Osteoglossum bicirrhosum). Bull. Eur. Ass. Fish Pathol. 2019, 39, 83.

23. Antuofermo, E.; Pais, A.; Polinas, M.; Cubeddu, T.; Righetti, M.; Sanna, M.A.; Prearo, M. Mycobacteriosis caused by Mycobacterium marinum in reared mullets: First evidence from Sardinia (Italy). J. Fish Dis. 2016, 40, 327-337. [CrossRef] [PubMed]

24. Katoh, K.; Standley, D.M. MAFFT Multiple sequence alignment software version 7: Improvements in performance and usability. Mol. Biol. Evol. 2013, 30, 772-780. [CrossRef]

25. Schmidt, H.A.; Strimmer, K.; Vingron, M.; Von Haeseler, A. Tree-puzzle: Maximum likelihood phylogenetic analysis using quartets and parallel computing. Bioinformatics 2002, 18, 502-504. [CrossRef]

26. Schmidt, H.A.; Von Haeseler, A. Phylogenetic inference using maximum likelihood methods. In The Phylogenetic Handbook; Cambridge University Press: Cambridge, UK, 2012; pp. 181-209.

27. Ronquist, F.; Huelsenbeck, J.P. MrBayes 3: Bayesian phylogenetic inference under mixed models. Bioinformatics 2003, 19, 1572-1574. [CrossRef]

28. Scarpa, F.; Cossu, P.; Delogu, V.; Lai, T.; Sanna, D.; Leasi, F.; Norenburg, J.L.; Casu, M.; Curini-Galletti, M. Molecular support for morphology-based family-rank taxa: The contrasting cases of two families of Proseriata (Platyhelminthes). Zool. Scr. 2017, 46, 753-766. [CrossRef]

29. Miller, M.; Pfeiffer, W.; Schwartz, T. Creating the CIPRES Science Gateway for inference of large phylogenetic trees. In Proceedings of the 2010 Gateway Computing Environments Workshop (GCE), New Orleans, LA, USA, 14 November 2010.

30. Gelman, A.; Rubin, D.B. Inference from iterative simulation using multiple sequences. Stat. Sci. 1992, 7, 457-472. [CrossRef]

31. Scarpa, F.; Cossu, P.; Sanna, D.; Lai, T.; Casu, M.; Curini-Galletti, M. New insights on the genus Otoplana Du Plessis, 1889 (Platyhelminthes: Proseriata), with description of two new species from the Canary Islands. Mar. Biodivers. 2017, 49, 2075-2087. [CrossRef]

32. Duchene, S.; Holt, K.E.; Weill, F.-X.; Le Hello, S.; Hawkey, J.; Edwards, D.J.; Fourment, M.; Holmes, E.C. Genome-scale rates of evolutionary change in bacteria. Microb. Genom. 2016, 2. [CrossRef]

33. Lattos, A.; Giantsis, I.A.; Karagiannis, D.; Michaelidis, B. First detection of the invasive Haplosporidian and Mycobacteria parasites hosting the endangered bivalve Pinna nobilis in Thermaikos Gulf, North Greece. Mar. Environ. Res. 2020, 155, 104889. [CrossRef]

34. López-Sanmartín, M.; Catanese, G.; Grau, A.; Valencia, J.; García-March, J.R.; Navas, J.I. Real-Time PCR based test for the early diagnosis of Haplosporidium pinnae affecting fan mussel Pinna nobilis. PLoS ONE 2019, 14, e0212028. [CrossRef] [PubMed]

35. Maeno, Y.; Yurimoto, T.; Nasu, H.; Ito, S.; Aishima, N.; Matsuyama, T.; Kamaishi, T.; Oseko, N.; Watanabe, Y. Virus-like particles associated with mass mortalities of the pen shell Atrina pectinata in Japan. Dis. Aquat. Org. 2006, 71, 169-173. [CrossRef] [PubMed] 
36. Secci, M.; Biancacci, C.; Giglioli, A.; Loddo, D.; Pasquini, V.; Addis, P. Geostatistical approach to investigate spatial patterns of the endangered fan mussel Pinna nobilis (Linnaeus, 1758). Reg. Stud. Mar. Sci. 2019, 32, 100884. [CrossRef]

37. Patarnello, T.; Volckaert, F.A.M.J.; Castilho, R. Pillars of Hercules: Is the Atlantic-Mediterranean transition a phylogeographical break? Mol. Ecol. 2007, 16, 4426-4444. [CrossRef]

38. Addis, P.; Secci, M.; Brundu, G.; Manunza, A.; Corrias, S.; Cau, A. Density, size structure, shell orientation and epibiontic colonization of the fan mussel Pinna nobilis L. 1758 (Mollusca: Bivalvia) in three contrasting habitats in an estuarine area of Sardinia (W Mediterranean). Sci. Mar. 2009, 73, 143-152. [CrossRef]

39. Rabaoui, L.; Tlig-Zouari, S.; Cosentino, A.; Ben Hassine, O.K. Associated fauna of the fan shell Pinna nobilis (Mollusca: Bivalvia) in the northern and eastern Tunisian coasts. Sci. Mar. 2009, 73, 129-141. [CrossRef]

40. Rabaoui, L.; Tlig-Zouari, S.; Ben Hassine, O.K. Distribution and habitat of the fan mussel Pinna nobilis Linnaeus, 1758 (Mollusc: Bivalvia) along the northern and eastern Tunisian coasts. Cah. Biol. Mar. 2008, 49, 67-78.

41. García-March, J.R.; García-Carrascosa, A.M.; Cantero, A.L.P.; Wang, Y.-G. Population structure, mortality and growth of Pinna nobilis Linnaeus, 1758 (Mollusca, Bivalvia) at different depths in Moraira bay (Alicante, Western Mediterranean). Mar. Biol. 2006, 150, 861-871. [CrossRef]

42. Nikula, R. Phylogeography of Cerastoderma glaucum (Bivalvia: Cardiidae) across Europe: A major break in the Eastern Mediterranean. Mar. Biol. 2003, 143, 339-350. [CrossRef]

43. Calvo, M.; Templado, J.; Oliverio, M.; Machordom, A. Hidden Mediterranean biodiversity: Molecular evidence for a cryptic species complex within the reef building vermetid gastropod Dendropoma petraeum (Mollusca: Caenogastropoda). Biol. J. Linn. Soc. 2009, 96, 898-912. [CrossRef]

44. Cossu, P.; Dedola, G.L.; Scarpa, F.; Sanna, D.; Lai, T.; Maltagliati, F.; Curini-Galletti, M.; Casu, M. Patterns of spatial genetic variation in Patella ulyssiponensis: Insights from the western Mediterranean marine ecoregion. Hydrobiologia 2015, 755, 39-55. [CrossRef]

45. Cabanellas-Reboredo, M.; Vázquez-Luis, M.; Mourre, B.; Álvarez, E.; Deudero, S.; Amores, Á.; Addis, P.; Ballesteros, E.; Barrajón, A.; Coppa, S.; et al. Tracking a mass mortality outbreak of pen shell Pinna nobilis populations: A collaborative effort of scientists and citizens. Sci. Rep. 2019, 9, 1-11. [CrossRef]

46. Ford, S.E.; Haskin, H.H. History and epizootiology of Haplosporidium nelsoni (MSX), an oyster pathogen in Delaware Bay, 1957-1980. J. Invertebr. Pathol. 1982, 40, 118-141. [CrossRef]

47. Haskin, H.H.; Andrews, J.D. Uncertainties and speculations about the life cycle of the eastern oyster pathogen Haplosporidium nelsoni (MSX). Dis. Process. Mar. Bivalve Molluscs 1988, 18, 5-22.

48. Hudson, E.; Hill, B. Impact and spread of bonamiasis in the UK. Aquaculture 1991, 93, 279-285. [CrossRef]

49. Hofmann, E.; Ford, S.; Powell, E.; Klinck, J.M. Modeling studies of the effect of climate variability on MSX disease in eastern oyster (Crassostrea virginica) populations. Ecol. Etiol. New. Emerg. Mar. Dis. 2001, 17, 195-212. [CrossRef]

50. Burreson, E.M.; Ford, S.E. A review of recent information on the Haplosporidia, with special reference to Haplosporidium nelsoni (MSX disease). Aquat. Living Resour. 2004, 17, 499-517. [CrossRef]

51. Laing, I.; Dunn, P.; Peeler, E.; Feist, S.; Longshaw, M. Epidemiology of Bonamia in the UK, 1982 to 2012. Dis. Aquat. Org. 2014, 110, 101-111. [CrossRef]

52. De Carvalho, C.C.C.R.; Da Fonseca, M.M.R. The remarkable Rhodococcus erythropolis. Appl. Microbiol. Biotechnol. 2005, 67, 715-726. [CrossRef]

53. Ward, A.L.; Reddyvari, P.; Borisova, R.; Shilabin, A.G.; Lampson, B.C. An inhibitory compound produced by a soil isolate of Rhodococcus has strong activity against the veterinary pathogen R. equi. PLoS ONE 2018, 13, e0209275. [CrossRef] [PubMed]

54. Kitagawa, W.; Tamura, T. Three Types of Antibiotics Produced from Rhodococcus erythropolis Strains. Microbes Environ. 2008, 23, 167-171. [CrossRef] [PubMed]

55. Olsen, A.B.; Birkbeck, T.; Nilsen, H.; MacPherson, H.; Wangel, C.; Myklebust, C.; Laidler, L.; Aarflot, L.; Thoen, E.; Nygard, S.; et al. Vaccine-associated systemic Rhodococcus erythropolis infection in farmed Atlantic salmon Salmo salar. Dis. Aquat. Org. 2006, 72, 9-17. [CrossRef] [PubMed]

(C) 2020 by the authors. Licensee MDPI, Basel, Switzerland. This article is an open access article distributed under the terms and conditions of the Creative Commons Attribution (CC BY) license (http://creativecommons.org/licenses/by/4.0/). 